\title{
Trabalho e práxis e sua relação com as pedagogias de Célestin Freinet e de Paulo Freire
}

Flávio Boleiz Júnior ${ }^{\prime}$

\begin{abstract}
Resumo
Este artigo é fruto de uma pesquisa bibliográfica que investigou os trabalhos pedagógicos de Célestin Freinet - em suas atividades docentes e sua militância por uma educação popular no interior da França - e de Paulo Freire - em suas atividades de alfabetização de adultos na região nordeste do Brasil, antes do golpe militar de 1964, em seus trabalhos educacionais no exílio e em sua atuação como Secretário da Educação na cidade de São Paulo. Ambos desenvolveram sistemas próprios de educação, tendo como base a categoria trabalho e como objetivo a realização de uma educação popular. Freinet procurou desenvolver um modo de fazer educação primária de qualidade num meio pobre, a partir de uma concepção que colocava o educando no centro do trabalho educativo em todas as atividades escolares. Este artigo apresenta como um e outro, respeitadas as peculiaridades de seus trabalhos e dos contextos em que atuaram, ainda que se utilizando de nomenclaturas diferentes e lidando com sujeitos de idades completamente diversas, construíram práticas populares de ensino fundamentados nos princípios de educação e trabalho, tendo como base para suas obras o processo pedagógico enquanto trabalho humano.
\end{abstract}

\section{Palavras-chave}

Freinet - Freire - Educação popular - Educação e trabalho. 


\title{
Work and praxis, and their relation to the pedagogies of Célestin Freinet and Paulo Freire
}

Flávio Boleiz Júnior ${ }^{1}$

\begin{abstract}
This article is the result of bibliographic research that investigated the pedagogical work of Célestin Freinet - in his teaching activities and struggle for popular education in France - and by Paulo Freire - in his adult literacy activities in the Northeast region of Brazil before the military coup of 1964 -, in his educational work while in exile and in his actions as Secretary of Education of the city of São Paulo. They both developed their own teaching systems having the category of labor as a basis and the undertaking of popular education as an objective. Freinet sought to develop a method of quality primary education within an economically poor environment with the underlying conception that the learner was at the center of all educational activities. Bearing in mind the particularities of their work and the contexts in which they acted, this article states that, despite using different nomenclature and dealing with subjects of completely different ages, both authors developed popular teaching practices on the basis of the principles of education and labor, grounding their work on the pedagogical process as human labor.
\end{abstract}

\section{Keywords}

Freinet - Freire - Popular education - Education and labor.

I- Universidade Federal do Rio Grande

do Norte. Natal, RN, Brasil

Contact: boleiz@ufrnet.br 
Na configuração ontológica do humano, o significado da noção de trabalho relaciona-se com a característica específica dos sujeitos, de transcender a Natureza na conformação de sua condição de homem.

Segundo Friedrich Engels, o trabalho "é a condição básica e fundamental de toda a vida humana. E em tal grau que, até certo ponto, podemos afirmar que o trabalho criou o próprio homem" (2009, p. 11), que, submetendo as imposições da natureza, vai construindo o mundo dos humanos, na medida em que suas mãos, nas palavras de Paulo Freire, "se vão fazendo, cada vez mais, mãos humanas, que trabalhem e transformem o mundo" (FREIRE, 2002, p. 31, grifo meu).

Engels associa o trabalho diretamente à produção da riqueza quando argumenta que “o trabalho é a fonte de toda a riqueza, [conforme] afırmam os economistas. Assim é, com efeito, ao lado da natureza, encarregada de fornecer os materiais que ele converte em riqueza" (ENGELS, 2009, p. 11).

Karl Marx, por sua vez, ao tratar da questão da riqueza das sociedades capitalistas, afirma que a mercadoria é sua forma essencial. Explica que "a mercadoria é, antes de tudo, um objeto externo, uma coisa, a qual pelas suas propriedades satisfaz necessidades humanas de qualquer espécie” (MARX, 1983a, p. 45), não importando se tais necessidades derivam do estômago ou das fantasias. Para o filósofo alemão, não importa tampouco se tal objeto externo atende a necessidade humana imediatamente, como objeto de consumo, ou de maneira indireta, como meio de produção de outro objeto; entretanto, "cada uma dessas coisas é um todo de muitas propriedades e pode, portanto, ser útil sob diversos aspectos" (MARX, 1983a, p. 45).

As coisas que o homem produz por meio de seu trabalho destinam-se a diferentes utilidades e, para Marx, "a utilidade de uma coisa faz dela um valor de uso" (MARX, 1983a, p. 45). Dessa maneira, o valor de uso de determinada coisa se refere àquilo para o que tal coisa serve. Há coisas com mais de um valor de uso, da mesma maneira que há mais de uma coisa com valor de uso igual. Uma xícara, por exemplo, pode ser utilizada como instrumento de medida para um determinado ingrediente de uma receita, da mesma maneira, como um recipiente para se beber um líquido. Um copo, mesmo sendo diferente de uma xícara, pode também destinar-se a essas mesmas utilidades. Assim sendo, pode-se dizer que tanto a xícara quanto o copo têm como valores de uso medir ingredientes de uma receita, bem como servir para conter um líquido que se deseje beber. A produção da vida humana só é possivel em função da peculiaridade histórica que caracteriza os homens enquanto sujeitos históricos da ação criadora que produz sua própria história, na medida em que vão produzindo seus valores de uso.

Em função de sua constituição como ser ético, o homem se pronuncia diante da Natureza, não aceitando passivamente as imposições desta, mas criando novos valores e escolhendo seu modo de estar no mundo, o que constitui a própria essência humana - sua natureza ${ }^{1}$. Produzir valores de uso a partir das escolhas que advêm dos valores estabelecidos para bem-estar no mundo demanda, pois, uma postura diante das próprias condições de vida que é especificidade dos homens e que lhes permite transcender a Natureza, na medida em que, não se conformando diante de suas imposições, submetem-na, transformando-a, derivando a construção de própria condição de humanidade dos homens. Assim o é, em primeiro lugar, porque somente os homens estabelecem eticamente valor, que se manifesta por meio de suas escolhas e interesses, para os quais se colocam em atividade de produção da transformação transcendente da Natureza que os submete. Em segundo lugar, essa transcendência de que somente os homens são capazes lhes garante outro fator que identifica sua condição de humanidade, que é a capacidade de

1- Neste trabalho, utiliza-se a palavra Natureza (com N maiúsculo) para referência ao mundo material em que vive o ser humano, a qual existe independentemente das atividades humanas. Já para a referência ao conjunto de peculiaridades que caracterizam uma espécie, utiliza-se a palavra natureza (com n minúsculo). 
se constituírem como sujeitos de sua própria vida, o que os faz serem históricos, na medida em que, transformando o mundo natural que os abriga, criam um outro mundo - transcendente - que se sobrepõe àquele e que transforma a si próprios.

Para melhor explicar o que aqui estamos chamando de condição de humanidade, procuraremos caracterizar o ser humano em suas especificidades e peculiaridades.

É fato que a Natureza se impõe ao homem - tal como se impõe a tudo. Suas leis universais o submetem a uma série de necessidades e não o livram da fome, do frio, da sede, enfim, das necessidades que naturalmente lhe cobram a sobrevivência. Em decorrência de tais imposições naturais, os homens precisam coletar seus alimentos, acercar-se do calor, procurar por mananciais etc. Enquanto que o animal, ao não se deparar com alimento para matar sua fome, com o fogo ou o lugar mais quente para se aquecer ou com o manancial para se saciar, coloca-se à mercê das circunstâncias e, penosamente, deixa-se morrer, com o homem, a situação se apresenta de maneira completamente diferente. 0 homem se posiciona diante da realidade que se lhe impõe e, por sua livre decisão, transforma o meramente natural, de modo que, segundo José Ortega y Gasset,

\begin{abstract}
si, por falta de incendio o de caverna, no puede ejercitar la actividad o hacer de calentarse, o por falta de frutos, raíces, animales, la de alimentarse, el hombre pone en movimiento una segunda línea de actividades: hace fuego, hace un edificio, hace agricultura o cacería. (ORTEGA Y GASSET, 2002, p. 25-26).
\end{abstract}

Os homens gozam dessa característica que os torna diferentes dos demais seres. Trata-se da capacidade de se desprender, ainda que temporariamente, das urgências vitais, libertando-se delas para poder se dedicar a outra gama de atividades, para além daquelas que configuram a satisfação de necessidades naturais. Como afirma Vitor Henrique Paro, “o animal, como ser indiferenciado da natureza, não realiza trabalho humano, já que não busca objetivos livremente, colocando-se, portanto, no âmbito da pura necessidade" (PARO, 1988, p. 19, grifo no original). Ortega y Gasset pondera que "mientras todos los demás seres coinciden con sus condiciones objetivas - con la naturaleza o circunstancia -, el hombre no coincide con ésta, sino que es algo ajeno y distinto de su circunstancia” (ORTEGA Y GASSET, 2002, p. 27). Comparando o homem com os demais animais, mesmo aqueles superiores, mais próximos, Engels afirma peremptoriamente que "nem um só ato planificado de nenhum animal pôde imprimir na natureza o selo de sua vontade. Só o homem pôde fazê-lo" (ENGELS, 2009, p. 23).

A capacidade que os homens possuem de se afastar de seu repertório de atos naturais é que lhes possibilita transcender a Natureza, mediante sua vontade e sua inconformidade para com a inexorabilidade do que está posto pelo que o mundo é. Ortega y Gasset é conclusivo ao afırmar que "esta reacción contra su contorno, este no resignarse contentándose con lo que el mundo es, es lo específico del hombre" (2002, p. 32) .

0 não contentar-se com o que o mundo é determina aos homens um tipo diverso de necessidade. Torna-se-lhes necessário transformar o mundo para fazê-lo como não é. Para tanto, os homens se deparam com um problema que somente a si mesmos podem interpor: o das escolhas. Os homens se colocam continuamente em situação de terem que escolher o que os favorece estar bem no mundo. Diante das características da realidade que os cerca, os homens efetivamente criam valor, determinando o que é bom ou não para si mesmos. Essa possibilidade ética de criar valor para as coisas e de fazer escolhas, de optar pelo que consideram que é bom e pelo que não é, move os homens na direção das transformações que imporão ao mundo tal como é para que se transforme no mundo tal como os homens o querem, numa espécie 
de reformulação ou, melhor dizendo, numa transcendência da Natureza.

0 homem se relaciona com a Natureza pelo trabalho. Por sua vez, o significado de trabalho é "atividade orientada a um fim", como diz Marx (1983a, p. 150). 0 imperativo permanente dos humanos em exercer sua característica ética de fazer escolhas, mediante os valores que criam, determina a perpétua necessidade de readequarem o mundo às suas necessidades, quereres e desejos. Por isso, ao avaliar a realidade e escolher o modo como lhes convém que ela passe a ser, os homens estabelecem fins a serem alcançados e, em função deles, planejam, elaboram e executam as atividades necessárias para atingi-los. É por meio dessas atividades que realizam em busca da transformação do mundo que os homens transcendem a Natureza e, ao fazê-lo, constituem-se como seres históricos, transformadores da realidade, produzindo, assim, sua condição de humanidade.

Ao refletir sobre o trabalho tal como explicitado acima, podemos afirmar que o educador se relaciona com o educando pelo processo pedagógico. Por sua vez, o processo pedagógico, enquanto atividade adequada à formação dos educandos, é trabalho, pois é "atividade orientada a um fim" (MARX, 1983a, p. 150), como acabamos de ver. Nessa relação específica entre trabalhador e trabalho, o processo pedagógico se apresenta como procedimento em que trabalhador e objeto de trabalho se inter-relacionam dialeticamente. Tanto o educador-trabalhador contribui para a transformação do educando-objeto-de-trabalho quanto o educando-trabalhador contribui para a transformação do educador-objeto-de-trabalho.

Essa noção de processo pedagógico como trabalho humano contribui para desvelar a implicação do trabalho como categoria central nas pedagogias de Freinet e de Freire.

Aqui vale a pena destacar a ideia de Paulo Freire de que "quem ensina aprende ao ensinar e quem aprende ensina ao aprender" (2006, p. 23), a qual, analisada a partir dessa ideia de processo pedagógico enquanto trabalho humano, revela um educador que apoia sua concepção educativa na noção de trabalho, como acabamos de demonstrar.

Transformando a Natureza e o mundo em que vivem, os homens transformam a si próprios. Donde o caráter fundamentalmente educativo do trabalho, que lhes permite a autotransformação, na medida em que transformam o mundo e se apropriam do mundo novo que se constitui daí, atualizando-se histórica e culturalmente. Para Célestin Freinet, essa apropriação do mundo novo, construído pelos humanos, significa sua conquista do mundo e, para ele, "esta conquista efetua-se pelo trabalho, que é a atividade pela qual o individuo satisfaz as suas grandes necessidades psicológicas e psíquicas a fim de adquirir o poder que lhe é indispensável para cumprir o seu destino" (FREINET, 1969, p. 44, grifos meus).

No mundo regido pelo modo de produção capitalista, as ações, desejos, necessidades e gostos humanos - as necessidades criadas pelo homem para além do que se caracteriza como suas necessidades naturais - acabam por demandar as mercadorias - todas elas valores de uso - a que se referiu Marx. Na permanente empreitada de transformação do mundo, os homens transformam aquilo que está na Natureza numa outra coisa que só eles podem fazer. Essa atividade realizada pelos homens em consequência de suas escolhas que visam a lograr determinados objetivos Marx precisa como trabalho. Para ele,

antes de tudo, o trabalho é um processo entre o homem e a Natureza, um processo em que o homem, por sua própria ação, media, regula e controla seu metabolismo com a Natureza. Ele mesmo se defronta com a matéria natural como uma força natural. Ele põe em movimento as forças naturais pertencentes à sua corporalidade, braços e pernas, cabeça e mãos, a fim de apropriar-se da matéria natural numa forma útil para sua própria vida. Ao atuar, por meio desse movimento, sobre a Natureza 
externa a ele e ao modificá-la, ele modifica, ao mesmo tempo, sua própria natureza. (MARX, 1983a, p. 149).

A atividade realizada pelos homens com a finalidade de transformação do elemento natural, que se caracteriza como atividade orientada a um fim, resulta de um objetivo que já existia em sua imaginação. Ao realizar trabalho, o trabalhador "não apenas efetua uma transformação da forma da matéria natural; realiza, ao mesmo tempo, na matéria natural seu objetivo, que ele sabe que determina, como lei, a espécie e o modo de sua atividade e ao qual tem de subordinar sua vontade" (MARX, 1983a, p. 150).

Por meio do trabalho, os homens se constituem como sujeitos históricos, quer dizer, autores de um novo modo de ser e estar no mundo, diferente de todos os demais seres da Natureza.

Paulo Freire é categórico ao relacionar o trabalho com a transformação do mundo e a criação da cultura humana. Ele afırma que "transformando a realidade natural com seu trabalho, os homens criam o seu mundo. Mundo da cultura e da história que, criado por eles, sobre eles se volta, condicionando-os. Isto é o que explica a cultura como produto, capaz ao mesmo tempo de condicionar seu criador" (FREIRE, 1982, p. 27).

Também Engels destaca a função histórica do trabalho na transformação da cultura humana quando argumenta que, com o passar dos tempos,

os homens foram aprendendo a executar operações cada vez mais complexas, a se propor e alcançar objetivos cada vez mais elevados. 0 trabalho mesmo se diversificava e aperfeiçoava de geração em geração, estendendo-se cada vez a novas atividades. À caça e à pesca veio juntar-se a agricultura e, mais tarde, a fiação e a tecelagem, a elaboração de metais, a olaria e a navegação. Ao lado do comércio e dos ofícios apareceram, finalmente, as artes e as ciências; das tribos saíram as nações e os Estados. Apareceram o direito e a política e, com eles, o reflexo fantástico das coisas no cérebro do homem: a religião. (ENGELS, 2009, p. 20).

0 trabalho humano é mediação para transformação do homem em humano-histórico. 0 trabalho caracteriza e explica a sociedade, proporcionando-lhe o sentido histórico. Tudo que existe para além do meramente natural foi feito por meio do trabalho e nada do que existe no mundo da cultura humana poderia existir sem ele. Aprofundando o significado dessa capacidade criadora dos humanos por meio do trabalho, Paro distingue-o como "a mediação que o homem necessita para construir-se historicamente" e diz que

a centralidade do trabalho na sociedade está precisamente em seu poder de explicação dessa sociedade e da história, não podendo, entretanto, ser confundido com a razão de ser e o objetivo último do homem enquanto ser histórico. 0 trabalho possibilita essa historicidade, não é a razão de ser dela. 0 trabalho é central porque possibilita a realização do bem viver, que é precisamente o usufruir de tudo que o trabalho pode propiciar. (PARO, 2001, p. 18 , grifos no original).

Ao exercer suas atividades adequadas à transformação da Natureza, os homens não atuam de modo isolado. 0 trabalho se constitui atividade que se realiza de maneira social. Os seres humanos realizam seu trabalho em contato constante com outros seres humanos, o qual os caracteriza pela liberdade de que dispõem diante das imposições naturais, por poder transcendê-las por meio do trabalho. A necessidade de transformar a Natureza, ao demandar a atuação coletiva dos homens em sua realização, caracteriza-os, também, como seres sociais.

0 ser social do homem se explicita na maneira que ele encontrou de superar sua própria pequenez diante da Natureza. Sozinho, o homem não consegue produzir sua existência 
e, por isso mesmo, criou uma maneira de dividir suas atividades com outros homens, de modo que socialmente se tornou possível produzir tudo aquilo que, historicamente, construiu e transformou em suas novas necessidades, para além do que lhe estava disponível na própria Natureza. Em outras palavras, a divisão social do trabalho proporcionou ao ser humano a força que necessitava para conseguir transcender a Natureza, de forma social.

0 homem, em função da cultura, que produz e transforma a Natureza, é livre. Paradoxalmente, se o homem não tiver vontade e não aplicar sua energia para realizar a sua vontade, ele não existe, pois só existindo livre é que pode existir como ser necessário da Natureza que, por meio de sua natureza, a transforma e cria o mundo e a cultura que o fazem humano.

Quando um indivíduo, mesmo que sozinho, produz um dado produto com a intenção de trocá-lo por outro produto de que necessita para sua subsistência, já realiza, ali mesmo em sua empresa individual, um trabalho de caráter social, visto que a troca de seu produto só é possível porque pode se relacionar com outro indivíduo que também produziu algo que planejava trocar. 0 caráter social do trabalho e a necessária condição plural da existência humana se evidenciam diante da realidade em que o homem realiza o esforço de produção da sua própria vida.

A transformação das condições materiais impostas pela Natureza são muito mais facilmente realizadas quando o trabalho que as possibilita é fruto de dispêndio coletivo de energia. Segundo Paro,

desde as épocas mais primitivas [...] os homens perceberam, por força da inevitabilidade de suas relações recíprocas, que os objetivos a que se propunham podiam ser atingidos mais efetivamente e com economia de recursos quando, em lugar de agirem isoladamente, suas ações fossem conjugadas na busca de objetivos comuns. (PARO, 1988, p. 22).
Não podemos deixar de mencionar o fato de que, com o desenvolvimento do capitalismo, o trabalho passou por uma série de processos que acabaram por distanciar cada vez mais o trabalhador do resultado de seu trabalho. Para que se possa ter ideia da importância desse fato, é necessário que se compreenda o modo como em geral se dá o trabalho e sua importância para a realização da natureza humana. Para tanto, convém partir da ponderação de Marx, que afirma que "os elementos simples do processo de trabalho são a atividade orientada a um fim ou o trabalho mesmo, seu objeto e seus meios" (MARX, 1983a, p. 150).

0 trabalho em si já está aí explicitado, enquanto que objeto de trabalho e meios de trabalho demandam uma melhor explicação. 0 objeto de trabalho é aquilo que sofre transformação durante o processo de trabalho, pois, em tal processo, "a atividade do homem efetua [...] mediante o meio de trabalho, uma transformação do objeto de trabalho, pretendida desde o princípio" (MARX, 1983a, p. 151). Os meios de trabalho, ou instrumentos de trabalho, por sua vez, dizem respeito à mediação que se coloca entre o homem e o objeto de trabalho para que se dê sua transformação. Nas palavras de Marx, "o meio de trabalho é uma coisa ou um complexo de coisas que o trabalhador coloca entre si mesmo e o objeto de trabalho e que lhe serve como condutor de sua atividade sobre esse objeto" (MARX, 1983a, p. 150). Os objetos de trabalho e os meios de trabalho conformam os meios de produção, que são "todos os elementos materiais que, direta ou indiretamente, participam do processo de produção" (PARO, 1988, p. 21).

A sociedade capitalista é constituída por dois grupos de interesse, que se formam, por um lado, por aqueles que são proprietários dos meios de produção - os capitalistas - e, por outro lado, pelos que são proprietários apenas da força de trabalho, que é a energia humana necessária para que se possa realizar trabalho - os trabalhadores. Trata-se das classes sociais que lutam em meio às relações sociais em 
defesa de interesses antagônicos, uma vez que os meios de produção não produzem sem o emprego da força de trabalho, ao mesmo tempo em que a força de trabalho não pode produzir sem o acesso aos meios de produção.

Em função dessa condição, os trabalhadores necessitam de meios de produção e não os possuem, ao mesmo tempo em que os capitalistas necessitam de força de trabalho para fazerem produzir seus meios de produção.

Os meios de produção constituem-se em causa e efeito diretamente ligados ao acúmulo de capital que, nas mãos de uns poucos indivíduos, foi-se amontoando enquanto dinheiro a serviço da obtenção de mercadorias, que, nas relações de mercado, constituem-se em mais dinheiro, gerando enriquecimento e acumulação de mais dinheiro e mais objetos de trabalho e instrumentos de trabalho.

0 resultado desse modo de relações que se desenvolvem entre capitalistas e trabalhadores se concretiza em um processo de exploração da classe proletária pela classe dominante; exploração essa caracterizada pela compra de força de trabalho e pela apropriação do excedente produzido pela classe trabalhadora, que, em suas jornadas de trabalho, produzem mais do que o necessário para a produção de sua própria vida.

A partir da compreensão desse contexto, pode-se entender a dramaticidade que representa, para o trabalhador, a alienação no processo de produção de que participa. Alienação significa separação, de modo que a cisão entre o trabalho e seu produto, provocada pela propriedade privada dos meios de produção, é real e não se supera meramente pela conscientização do trabalhador. Humanamente, por meio do trabalho, o homem se prolonga, para além de seu corpo físico, no produto de seu trabalho transformador da Natureza. Dessa maneira, a concentração dos meios de produção nas mãos de uma classe social legou aos trabalhadores a necessidade de transformar sua força de trabalho em produto de barganha, para superação de sua necessidade de produção da própria existência - por meio do trabalho. Numa sociedade organizada pelo embate dessas duas classes numericamente desiguais - o número de proprietários dos meios de produção é ínfımo se comparado ao dos meros proprietários da força de trabalho -, a concentração de poder nas mãos da minoria refletiu, por sua parte, a exploração da maioria, que, contando apenas com sua energia e disposição para trabalhar, passou a se ver expropriada do produto de seu trabalho no processo da atividade de produção. 0 fruto do trabalho humano, tal como o temos visto até aqui, é parte do próprio trabalhador. Sua produção consiste em criação cultural - superação da Natureza -, e o conceito de humano inclui o que ele faz, o produto de seu trabalho, uma vez que o produto é a aplicação de uma parte dele: sua energia vital foi aplicada para confecção do produto de seu trabalho e nele se encontra incorporado. $\mathrm{Na}$ sociedade caracterizada pelo modo de produção capitalista, por sua vez, os objetos produzidos pelo trabalhador não são dele, mas do seu patrão, que é o dono dos meios de produção que comprou sua força de trabalho, separando-o - alienando-o - do produto do trabalho, componente de sua natureza humana, juntamente com toda a energia investida em sua produção.

Com a grande massa de trabalhadores contando apenas com a possibilidade de dispor de sua força de trabalho como meio de sobrevivência, foi-se concentrando, ainda mais, o capital nas mãos de uma pequena quantidade de proprietários.

A mediação necessária ao homem para sua conformação humano-histórica, sob o modo de produção capitalista, transformouse em atividade subordinada ao mercado e ao capital. Dessa maneira, o trabalho deixou de representar mediação para uma vida boa para um viver bem, num mundo organizado em função da liberdade, em que os homens pudessem viver sua condição de sujeitos em relação de cooperação com os demais - para se transformar numa atividade degradante da 
condição humana. 0 trabalho se transformou em trabalho forçado, por meio do qual o trabalhador produz sua própria existência tendo que se submeter aos interesses dos proprietários do capital, única maneira de poder ter acesso aos meios de produção.

Para explicar a gênese da separação entre os meios de produção, que passaram a ser propriedade dos capitalistas, e da força de trabalho, Marx aborda a acumulação de capital que se iniciou em tempos pré-capitalistas e, ao fazê-lo, tece anedoticamente uma comparação entre os primórdios da acumulação e o pecado original das culturas judaico-cristãs:

Essa acumulação primitiva desempenha na Economia Política um papel análogo ao pecado original na Teologia. Adão mordeu a maçã e, com isso, o pecado sobreveio à humanidade. Explica-se sua origem contando-a como anedota ocorrida no passado. Em tempos muito remotos, havia, por um lado, uma elite laboriosa, inteligente e sobretudo parcimoniosa e, por outro, vagabundos dissipando tudo o que tinham e mais ainda. [...] os primeiros acumularam riquezas e os últimos, finalmente, nada tinham para vender senão sua própria pele. E desse pecado original data a pobreza da grande massa que até agora, apesar de todo seu trabalho, nada possui para vender senão a si mesma e a riqueza dos poucos, que cresce continuamente, embora há muito tenham parado de trabalhar. (MARX, 1983b, p. 261).

Após esta breve "explicação" da origem da acumulação de capital, Marx retoma as relações entre capital e trabalho. Dessa maneira, demonstra a realidade das origens da acumulação de capital que desvirtuou o significado primeiro do trabalho, enquanto processo de transformação histórica da humanidade, para determinar uma maneira opressora de relação entre o trabalho e seu fruto para o trabalhador.
As origens do capitalismo demandaram a transformação dos meios de produção e subsistência - assim como do dinheiro e das mercadorias daqueles que primitivamente acumularam riquezas - em capital. Para Marx,

essa transformação mesma só pode realizar-se em determinadas circunstâncias, que se reduzem ao seguinte: duas espécies bem diferentes de possuidores de mercadorias têm de defrontar-se e entrar em contato; de um lado, possuidores de dinheiro, meios de produção e meios de subsistência, que se propõem a valorizar a soma-valor que possuem mediante compra de força de trabalho alheia; do outro trabalhadores livres, vendedores da própria força de trabalho e, portanto, vendedores de trabalho. (MARX, 1983b, p. 262).

A polarização suscitada pela contraposição dessas duas classes sociais propiciou as circunstâncias fundamentais para o desencadeamento da produção capitalista: "A relação-capital pressupõe a separação entre os trabalhadores e a propriedade das condições da realização do trabalho" (MARX, 1983b, p. 262), de modo que, assim que a produção capitalista se estabelece, conserva essa separação, ao mesmo tempo em que a reproduz em escalas cada vez maiores. Tanto é assim que:

o processo que cria a relação-capital não pode ser outra coisa que o processo de separação de trabalhador da propriedade das condições de seu trabalho, um processo que transforma, por um lado, os meios sociais de subsistência e de produção em capital, por outro, os produtores diretos em trabalhadores assalariados. A assim chamada acumulação primitiva é, portanto, nada mais que o processo histórico de separação entre produtor e meio de produção. Ele aparece como "primitivo" porque constitui a pré-história do capital e do modo de produção que lhe corresponde. (MARX, 1983b, p. 262). 
Marx identifica como característica do modo de produção capitalista a alienação do trabalhador em relação a todos os meios de produção, de sorte que lhe sobra unicamente a própria força de trabalho como mercadoria a ser vendida no mercado. Essa característica resulta das primícias da acumulação do capital e da maneira como se deu historicamente o surgimento do capitalismo, cuja estrutura econômico-social "proveio da estrutura econômica da sociedade feudal. A decomposição desta liberou os elementos daquela" (MARX, 1983b, p. 262). Na medida em que o trabalhador deixou de fazer parte dos meios de produção - como era o caso dos escravos e dos servos - e se libertou do domínio das corporações - com suas regras e normas para aprendizes e oficiais - e das prescrições que limitavam o campo de atuação do trabalho, tornou-se livre para vender sua força de trabalho como se vende qualquer mercadoria, em qualquer lugar onde se necessite dela. Dirá Marx, entretanto, que "esses recém-libertados só se tornam vendedores de si mesmos depois que todos os seus meios de produção e todas as garantias de sua existência, oferecidas pelas velhas instituições feudais, foram-lhes roubados. E a história dessa sua expropriação está inscrita nos anais da humanidade com traços de sangue" (MARX, 1983b, p. 262). A alienação estabelecida no processo de trabalho acabou com a possibilidade do exercício da autonomia por parte da classe proletária para a realização da transformação do mundo da necessidade e de sua própria natureza humana. Tal ruptura, para além de afastar o trabalhador do produto de seu trabalho, separa o próprio homem de sua condição básica de humanidade que, no processo de trabalho, constitui-se a partir de sua produção. No modo de produção capitalista, a liberdade construída pelos homens em sua configuração humana, por meio da transcendência do mundo da necessidade, acabou por se configurar em subordinação daqueles que só possuem sua própria força de trabalho àqueles que detêm os meios de produção.

No mundo capitalista, em que as relações entre os homens se realizam, no mais das vezes, por meio das relações que se estabelecem entre as mercadorias que produzem, a importância do trabalho, no que diz respeito ao próprio modo de produção dos valores de uso, está diretamente ligada ao valor das mercadorias que os homens produzem e que se faz representar em seu valor de troca.

0 produto da atividade dos trabalhadores cumpre a função de mercadorias na medida em que se colocam no mercado como valores de uso a serem trocados por outros valores de uso. Como, obviamente, "casaco não se troca por casaco, o mesmo valor de uso pelo mesmo valor de uso" (MARX, 1983a, p. 50), é necessário que haja algo que sirva de parâmetro para comparação entre as diferentes mercadorias, para que possam ser comparadas e trocadas.

De acordo com Marx,

o valor de uso realiza-se somente no uso ou no consumo. Os valores de uso constituem o conteúdo material da riqueza, qualquer que seja a forma social desta. Na forma de sociedade a ser por nós examinada, eles constituem, ao mesmo tempo, os portadores materiais do valor de troca. (MARX, 1983a, p. 46).

0 valor de troca assume, então, a função de indicar de maneira proporcional a quantidade de determinado valor de uso que se pode trocar por outro. Uma certa mercadoria, como, por exemplo, uma dada quantia de açafrão, pode ser trocada por uma outra quantidade bem maior de farinha de trigo, por uma quantidade maior ainda de garrafas de água mineral ou por uma pequena quantidade de ouro. Portanto, uma mesma mercadoria possui vários valores de troca, e não apenas um. Entretanto, os valores do açafrão, da farinha de trigo, das garrafas de água mineral e do ouro têm que ser permutáveis entre si. Portanto, "primeiro: os valores de troca vigentes da mesma mercadoria expressam algo igual. Segundo, porém: o valor de troca só pode ser o modo de expressão, a 'forma de manifestação' de um conteúdo dele distinguivel” (MARX, 1983a, p. 46). 
Ainda no estudo das ideias de Marx, vemos que, "como valores de uso, as mercadorias são, antes de mais nada, de diferente qualidade, como valores de troca só podem ser de quantidade diferente, não contendo, portanto, nenhum átomo de valor de uso" (MARX, 1983a, p. 47). Assim sendo, na própria comparação visando à troca entre mercadorias, o valor de troca figura autonomamente no que tange ao valor de uso. 0 que resta em comum entre as mais diversas mercadorias não é, portanto, o valor de uso ou o valor de troca, mas o valor. E "o valor de uma mercadoria é determinado pela quantidade de trabalho despendido durante a sua produção" (MARX, 1983a, p. 47). Dizer que uma mercadoria tem mais valor do que outra significa dizer, portanto, que uma mercadoria incorpora mais trabalho humano do que outra. Além disso, "é [...] apenas o quantum de trabalho socialmente necessário para a produção de um valor de uso o que determina a grandeza de seu valor" (MARX, 1983a, p. 48).

0 trabalho como atividade humana é fonte e possibilidade de transformação da Natureza, de sua transcendência, ao mesmo tempo em que é meio de se produzir valores de uso, dotados de valor no capitalismo, pela incorporação da força de trabalho em sua produção.

0 trabalho é atividade humana que, na vida dos homens, além de garantir-lhes a condição de humanidade, possibilita-lhes incorporar valor a todas as suas realizações. Sua centralidade na compreensão da existência humana é fundamental para que se possam compreender as relações dos homens entre si e com a Natureza. Por isso, seria impossível pensar numa educação com o caráter de atualização histórico-cultural das novas gerações (PARO, 2008, p. 24) sem levar em conta sua relação com a categoria trabalho.

A importância da compreensão da centralidade da categoria trabalho no processo educacional se expressa, por exemplo, nas palavras de Paulo Freire, quando afirma que: transformar o mundo através de seu trabalho, "dizer" o mundo, expressá-lo e expressar-se são o próprio dos seres humanos.

A educação, qualquer que seja o nível em que se dê, se fará tão mais verdadeira quanto mais estimule o desenvolvimento desta necessidade radical dos seres humanos. (1982, p. 24).

Em vários pontos de sua obra, Freire aborda a importância do trabalho em sua relação com uma educação que ajude a transformar a maneira de os educandos atuarem sobre a Natureza externa e sobre a própria natureza. Para ele, uma educação legítima deve ser capaz de operar uma transformação na compreensão crítica dos envolvidos no processo educacional - educador e educandos - que atinja sua maneira de ponderar, de ver o mundo e de trabalhar, instaurando também uma nova maneira de pensar e se expressar.

Ao falar de seu trabalho na educação de jovens e adultos, desde o final da década de 1950 e começo da década de 1960, Freire revela que, junto com sua equipe de pesquisa e alfabetização, costumava "desafiar os alfabetizandos com um conjunto de situações codificadas de cuja decodificação ou 'leitura' resultava a percepção crítica do que é cultura, pela compreensão da prática ou do trabalho humano, transformador do mundo" (1989, p. 13).

A alta significação do trabalho nos livros que compõem a obra freiriana é evidente. Ao se referir à importância da alfabetização, em outro ponto de sua produção, o autor afirma que

a alfabetização se faz, então, um quefazer global, que envolve os alfabetizandos em suas relações com o mundo e com os outros. Mas, ao fazer-se este quefazer global, fundado na prática social dos alfabetizandos, contribui para que estes se assumam como seres do quefazer da práxis. Vale dizer, como seres que, transformando o mundo com seu trabalho, criam o seu mundo. Este mundo, criado 
pela transformação do mundo que não criaram e que constitui seu domínio, é o mundo da cultura que se alonga no mundo da história. (FREIRE, 1982, p. 17).

0 trabalho, no entender de Freire, constitui mediação entre homem e Natureza, na construção da cultura humana. Por isso, para o autor, os homens,

ao perceberem o significado criador e recriador de seu trabalho transformador, descobrem um sentido novo em sua ação, por exemplo, de cortar uma árvore, de dividi-la em pedaços, de tratá-los de acordo com um plano previamente estabelecido e que, ao ser concretizado, dá lugar a algo que já não é a árvore. Percebem, finalmente, que este algo, produto de seu esforço, é um objeto cultural. (FREIRE, 1982, p. 17).

A práxis humana na transformação do mundo é encarada por Freire como ato continuado de criação dos homens na produção de seu mundo. Por meio do seu trabalho, os homens transformam, criam e recriam a possibilidade de estar no mundo. Na medida em que vão inventando as condições de que necessitam e que desejam para seu bem-estar, produzem sua própria condição de criadores: "Para os seres humanos, como seres da práxis, transformar o mundo, processo em que se transformam também, significa impregná-lo de sua presença criadora, deixando nele as marcas de seu trabalho" (FREIRE, 1982, p. 55).

Também Célestin Freinet destaca em sua obra a importância do trabalho, relacionando-o com a educação. Para ele,

o que estimula e orienta o pensamento humano, o que justifica seu comportamento individual e social é o trabalho em tudo o que hoje tem de complexo e de socialmente organizado, o trabalho, motor essencial, elemento do progresso e da dignidade, símbolo de paz e de fraternidade. (1998, p. 168).
A ligação entre Freinet e o pensamento intelectual de esquerda de seu tempo é ponto importante a se conhecer para a compreensão da importância que dá à categoria trabalho em todo seu labor docente. Michele Cristine da Cruz Costa destaca a ligação de Freinet com o Partido Comunista Francês por um período de pelo menos 26 anos, quando em seu trabalho afırma que, “dos anos 1920 até 1946, Freinet se apresenta decididamente engajado ao lado dos docentes revolucionários, aderindo ao PCF (Partido Comunista Francês) e militando igualmente na Federação de Ensino (Sindicato Unitário)” (COSTA, 2008, p. 61).

Trabalho, para Freinet, incorpora tamanha importância que sua proposta é congregar ao ensino o trabalho prático e manual - para além apenas de seu conceito. Ele aposta numa educação que relacione diretamente instrução, ensino e trabalho como ferramentas primordiais para a formação das crianças. Freinet assevera:

[...] não me contentarei em ligar essa escola ao trabalho pelo intermédio falacioso das palavras e dos livros. Não repetirei essa traição, mas colocarei efetivamente o trabalho na base de toda a nossa educação. [...] Constatamos que o trabalho, que os ofícios estão, queiramos ou não, no centro da vida das crianças; constituem o substrato comprovado sobre o qual vamos construir todo o nosso edifício cultural. (FREINET, 1998, p. 168).

Além da importância do trabalho enquanto mediação para o processo educativo, Freinet destaca o interesse e a necessidade de trabalho para as próprias crianças. Para ele, o próprio jogo não é tão importante para a criança quanto o trabalho, pois afirma que

não há na criança necessidade natural do jogo; há apenas necessidade de trabalho, isto é, a necessidade orgânica de usar o potencial de vida numa atividade ao mesmo 
tempo individual e social, que tenha uma finalidade perfeitamente compreendida, de acordo com as possibilidades infantis, e que apresente uma grande amplitude de reações: fadiga-repouso; agitação-calma; emoção-tranquilidade; medo-segurança; risco-vitória. Além disso, é preciso que esse trabalho preserve uma das tendências psíquicas mais urgentes, sobretudo desta idade: o sentimento de potência, o desejo permanente de se superar e aos outros, de conquistar vitórias, pequenas ou grandes, de dominar alguém ou alguma coisa. (FREINET, 1998, p. 189-190, grifos no original).

Outros professores ligados à Escola Moderna, em sua maioria afiliados à Cooperativa da Educação Laica (CEL), fundada e dirigida por muitos anos por Freinet, também assumiram 0 trabalho como categoria central em sua faina educativa. De acordo com Jacques Gauthier,

como Freinet, muitos professores filhos de camponeses ou operários tentaram manter a autoestima e o sentido social do labor dos trabalhadores ao aderir e tomar responsabilidades nos partidos comunista ou socialista. Mas pouquíssimos tiveram a lucidez e a coragem de Freinet, até considerar os próprios alunos como parceiros na construção do conhecimento, como trabalhadores capazes de produzir bens materiais e intelectuais úteis e prazerosos para si e para os outros. (1997, p. 2).

Entretanto, apesar de se instituir como um fenômeno constitutivo da condição humana, como dito anteriormente, o trabalho na sociedade capitalista assume características que lhe outorgam qualidades contrárias à sua natureza. Segundo Ricardo Antunes, a sociedade capitalista o transforma em trabalho assalariado, alienado, fetichizado. 0 que era uma finalidade central do ser social converte-se em meio de subsistência. A "força de trabalho" (conceito-chave em Marx) torna-se uma mercadoria, ainda que especial, cuja finalidade é criar novas mercadorias e valorizar o capital. Convertese em meio e não primeira necessidade de realização humana. (ANTUNES, 2009, p. 8).

0 próprio Marx (2001) considera que, sob o capitalismo, a força de trabalho se torna uma mercadoria e o trabalhador, um ser estranho, meio de sua própria subsistência individual. De característica da própria condição de humanidade, o trabalho se transforma em degradante do ser social, causando alienação e estranhamento aos trabalhadores. 0 próprio ato de produção, resultado do trabalho já alienado, contribui para a efetivação do processo de alienação do trabalhador, que se perde do produto de seu trabalho. Dessa maneira, segundo Antunes, "sob o capitalismo, o trabalhador frequentemente não se satisfaz no trabalho, mas se degrada; não se reconhece, mas muitas vezes recusa e se desumaniza no trabalho" (ANTUNES, 2009, p. 9).

Se, por um lado, o trabalho é uma atividade que assume característica central na constituição do humano como ser histórico, apresentando-se como fenômeno fundamental para sua socialização e emancipação, por outro lado, o modo de produção capitalista impôs uma mutação em sua essência, que alterou seu significado e o transformou num complexo instrumento de desumanização do trabalhador.

Este artigo tomou por base a noção de trabalho, como atividade humana, que transcende a Natureza e que, com seu caráter social, efetiva a condição do humano enquanto ser plural, ao mesmo tempo em que outorga a condição de humanidade àqueles que o realizam em suas atividades transformadoras do mundo. 


\section{Referências}

ANTUNES, Ricardo. (org.) A dialética do trabalho: escritos de Marx e Engels. São Paulo: Expressão Popular, 2009.

COSTA, Michele Cristine da Cruz. 0 pensamento educacional de Célestin Freinet e suas aproximações aos ideais do movimento da Escola Nova. Araraquara, 2008. Dissertação (Mestrado em Educação Escolar) — Universidade Estadual Paulista, Faculdade de Ciências e Letras, 2008.

ENGELS, Friedrich . Sobre o papel do trabalho na transformação do macaco em homem. In: ANTUNES, Ricardo. (Org.) A dialética do trabalho: escritos de Marx e Engels. São Paulo: Expressão Popular, 2009. p. 11-28.

FREINET, Célestin. Para uma escola do povo. Lisboa: Editorial, 1969.

FREINET, Célestin. A educação do trabalho. São Paulo: Martins Fontes, 1998.

FREIRE, Paulo. Ação cultural para a liberdade e outros escritos. 6. ed., São Paulo: Paz e Terra, 1982.

FREIRE, Paulo. A importância do ato de ler em três artigos que se completam. São Paulo: Cortez, 1989.

FREIRE, Paulo. Pedagogia do oprimido. 32. ed., São Paulo: Paz e Terra, 2002.

FREIRE, Paulo. Pedagogia da autonomia: saberes necessários à prática educativa. 33. ed., São Paulo: Paz e Terra, 2006.

GAUTHIER, Jacques. A criança engenheira dos vegetais e senhora do fogo: devaneando com Célestin Freinet. Revista da Faced, Salvador, n. 1, p. 1-3, 1997.

MARX, Karl. 0 capital - Crítica da economia política. v. I. São Paulo: Abril Cultural, 1983a.

MARX, Karl. 0 capital - Crítica da economia política. v. l/ll. São Paulo: Abril Cultural, 1983b.

MARX, Karl. Manuscritos econômico-filosóficos. São Paulo: Martin Claret, 2001.

ORTEGA Y GASSET, José. Meditacion de la técnica y otros ensayos sobre ciencia e filosofia. Madrid: Alianza, 2002.

PARO, Vitor Henrique. Administração escolar: introdução crítica. 3. ed. São Paulo: Cortês, 1988.

PARO, Vitor Henrique. Parem de preparar para o trabalho!!! Reflexões acerca dos efeitos do neoliberalismo sobre a gestão e o papel da escola básica. In: PARO, Vitor Henrique. Escritos sobre educação. São Paulo: Xamã, 2001. p. 13-31.

PARO, Vitor Henrique. Educação como exercício do poder: crítica ao senso comum em educação. São Paulo: Cortez, 2008.

Recebido em: 09.01.2014

Aprovado em: 07.10.2014

Flávio Boleiz Júnior é doutor em educação e professor de fundamentos sócio-filosóficos da educação do Departamento de Fundamentos e Políticas da Educação do Centro de Educação da Universidade Federal do Rio Grande do Norte (UFRN). 